\title{
Erratum to: Early Life Risk Factors for Stroke and Cognitive Impairment
}

\author{
Ellen V. Backhouse ${ }^{1} \cdot$ Caroline A. McHutchison $^{1} \cdot$ Vera Cvoro $^{1} \cdot$ Susan D. Shenkin ${ }^{2}$ • \\ Joanna M. Wardlaw ${ }^{1}$
}

Published online: 30 July 2015

(C) Springer International Publishing AG 2015

Erratum to: Curr Epidemiol Rep (2015) 3:

DOI 10.1007/s40471-015-0051-7

In the original version of this article, credit for the images of Winston Churchill in Fig. 1 was inadvertently omitted. The images were reproduced with permission of Curtis Brown, London on behalf of Broadwater Collection.

The online version of the original article can be found at http://dx.doi.org/ 10.1007/s40471-015-0051-7.

\footnotetext{
Joanna M. Wardlaw

joanna.wardlaw@ed.ac.uk

Ellen V. Backhouse

ellen.backhouse@ed.ac.uk

Caroline A. McHutchison

caroline.mchutchison@ed.ac.uk

Vera Cvoro

vera.cvoro@ed.ac.uk

Susan D. Shenkin

susan.shenkin@ed.ac.uk

1 Centre for Clinical Brain Sciences, The University of Edinburgh, The Chancellors Building, 49 Little France Crescent, Edinburgh EH16 4SB, UK

2 Geriatric Medicine, Department of Clinical and Surgical Sciences, The University of Edinburgh, 51 Little France Crescent, Edinburgh EH16 4SB, UK
} 